\title{
Chronic Exposure to Carbon Monoxide at High Altitude: Effects on Mean Electrical Axis
}

\author{
R. COOPER, J. J. MCGRATH, ${ }^{1}$ S. DOOLEY AND M. T. KOPETZKY \\ Department of Physiology, Texas Tech University Health Sciences Center, Lubbock, TX 79430
}

\begin{abstract}
COOPER, R., J. J. MCGRATH, S. DOOLEY AND M. T. KOPETZKY. Chronic exposure to carbon monoxide at high altitude: Effects on mean electrical axis. PHYSIOL BEHAV 46(1) 75-79, 1989. - The effects of breathing CO continuously at high altitude on the mean electrical axis of the heart, hematocrit ratio and body weight were studied in laboratory rats. Laboratory rats were exposed for 6 weeks to: 100 or $500 \mathrm{ppm} \mathrm{CO} ; 15,000$ feet simulated high altitude (SHA); or 100 or $500 \mathrm{ppm} \mathrm{CO}$ at SHA. SHA decreased body weight significantly; $\mathrm{CO}$ and CO-SHA interaction had no significant effect on body weight. CO and SHA increased hematocrit ratio significantly; five hundred ppm CO increased hematocrit ratio to a greater extent than $100 \mathrm{ppm} \mathrm{CO}$. There was a significant interaction between $500 \mathrm{ppm}$ CO and SHA on hematocrit ratio. The mean electrical axis (MEA) was shifted to the right by SHA, and shifted to the left by $\mathrm{CO}$. The effect was dose dependent, with the greater left shift occurring with $500 \mathrm{ppm} \mathrm{CO}$. There was a significant interaction between $500 \mathrm{ppm} \mathrm{CO}$ and SHA on the MEA. These results indicate that, in general, the effects produced by 15,000 feet SHA are not intensified by $100 \mathrm{ppm} \mathrm{CO}$, but are intensified by $500 \mathrm{ppm} \mathrm{CO}$.
\end{abstract}

Carbon Monoxide High altitude Electrocardiogram Hypoxia Air pollution Mean electrical axis

THE physiological responses of mammals to chronic high altitude exposure have been well-studied; the most prominent responses include increased blood hemoglobin concentration caused by hypoxia (15), and right ventricular hypertrophy, caused by hypoxic pulmonary vasoconstriction (12). Likewise, the physiological responses to chronic carbon monoxide $(\mathrm{CO})$ exposure have been reasonably well-studied; the most prominent responses include increased blood hemoglobin caused by hypoxia (16), but left ventricular hypertrophy caused by increased cardiac work (9). Due to technical difficulties, there have been few studies of the long term effects of breathing $\mathrm{CO}$ at altitude (5). The lack of information in this area is a significant problem because over 2.2 million people living at altitudes in excess of $1524 \mathrm{~m}(5,000 \mathrm{ft})$, and countless tourists and other sojourners visiting high altitude areas during both the summer and winter months (8), are exposed to $\mathrm{CO}$ from automobiles, fireplaces and smoking.

In this study, we tried to analyze the chronic effects of $\mathrm{CO}$ at $15,000 \mathrm{ft}$ on the mean electrical axis (MEA), hematocrit ratio and body weight in the laboratory rat.

\section{METHOD}

\section{Exposure System}

The altitude chamber system used in these studies has been described previously (6). It consists of 6 cylindrical steel chambers connected to a central air supply duct. Each chamber is fabricated from a 2001 barrel and fitted with a clear, Lucite plastic door for observing the animals. The door is machined and fitted with an 0 ring to ensure a gas tight seal. Air enters the system through a Hepa filter and flows through each chamber $(55 \mathrm{l} / \mathrm{min}$ or 16 air changes/hr). Altitude, simulated by an Atlantic Fluidic's watersealed pump (Fluid-Vac, model A10) and a system of adjustable globe valves, is measured by an aircraft altimeter. $\mathrm{CO}$, provided in high-pressure steel cylinders, is introduced into the air-intake side of each chamber via a mass flow controller (Matheson Gas). Chamber atmosphere is sampled sequentially from the outflow duct of each chamber via a switching solenoid (ChronotrolLindberg Enterprises, Inc.). CO concentrations are measured continuously for $1 \mathrm{hr}$ with a nondispersive infrared analyzer system (Beckman) and recorded continually on a chart recorder (Houston Instruments).

\section{Animals}

Male, Fisher-344 rats (Sasco Inc.) were used in these studies. The rats weighed approximately $135 \mathrm{~g}$ and $200 \mathrm{~g}$, respectively, at the beginning of the $100 \mathrm{ppm} \mathrm{CO}$ and $500 \mathrm{ppm}$ CO studies. The animals were housed in shoe box cages (6/cage) placed in the exposure chambers; they were fed a commercial diet (Purina Rat

\footnotetext{
${ }^{1}$ Requests for reprints should be addressed to Dr. James J. McGrath.
} 




FIG. 1. ECG recording set ups: (A) Nose cone for administering gas mixture and halothane; (B) Saline-filled containers; (C) ECG panel; (D) Vent; (E) Plastic chamber in Faraday Cage.

Chow, Ralston Purina Co., St. Louis, MO) and provided tap water ad lib. Water was supplied in standard watering bottles and care was taken to fill the bottles completely so that air could not displace water from the bottles during the ascent to SHA.

There were two parts to this study: In the first, the animals were exposed to ambient (AMB), AMB $+100 \mathrm{ppm} \mathrm{CO}, 15,000 \mathrm{ft}$ altitude (SHA) and SHA + $100 \mathrm{ppm} \mathrm{CO}$; in the second, the animals were exposed to AMB, AMB $+500 \mathrm{ppm} \mathrm{CO}$, SHA, and SHA +500 ppm CO.

\section{Analytical Methods}

Blood samples obtained from the tail were used to measure hematocrit ratios, by the microhematocrit technique, and carboxyhemoglobin $(\mathrm{COHb})$ concentrations by the method of Small et al. (13). One hundred ppm $\mathrm{CO}$ caused a $\mathrm{COHb}$ concentration of $8.4 \pm 0.5 \%$ (Mean $\pm \mathrm{SE}$ ), whereas $500 \mathrm{ppm} \mathrm{CO}$ caused a $\mathrm{COHb}$ concentration of $39.0 \pm 1.7 \%$.

At the end of six weeks, ECG's were measured on each rat. All rats were treated equally during the ECG recordings, and the time required to remove the rat from the chamber and begin recording did not exceed 15 minutes.

The rats were anesthetized with halothane administered via a nose cone (Fig. 1); the cone, fabricated from silicone rubber fit loosely over the rat's nose. A vented box was used to contain the rat and the apparatus required for recording the ECG. A vacuum line was attached to a port on top of the box and the box was placed in an aluminum Faraday cage. The animal and the apparatus could be manipulated via an opening in the side of the box; the opening was covered with a screen during the exposure.

To record the ECG, the rat was placed on a platform and its legs were placed into containers filled with a $10 \% \mathrm{NaCl}$ solution. Individual wires from three of the leg containers (right front leg, left front leg, left rear leg) were fastened to a panel; the panel had connectors to which the corresponding leads from the ECG recorder were attached. The ground lead from the ECG recorder was attached to the Faraday cage.

The ECG recordings were taken in a standard sequence (lead I, lead II, lead III). The mean electrical axis obtained from the recordings of the three common leads was determined by the common triaxial reference system according to the method of Burch and Winsor (2).

The effects of altitude and $\mathrm{CO}$ were assessed by two-way analysis of variance (ANOVA) with the Stats Plus ANOVA procedure (Human Systems Dynamics, Northridge, CA). A $p$ value of less than 0.05 was the minimal level of significance.

\section{RESULTS}

Body weights increased in all groups throughout the 6-week exposure (Fig. 2). At the end of the experiment, body weights in both the 100 and $500 \mathrm{ppm} \mathrm{CO}$ studies were significantly lower $(p<0.001)$ in the SHA than in the AMB groups. There were no significant differences in body weight between groups due to $\mathrm{CO}$ treatment nor was there a significant interaction between SHA and $\mathrm{CO}$ on body weight.

Hematocrit ratios increased with both $\mathrm{CO}$ and SHA (Fig. 3). At the end of the experiment, hematocrit ratios were significantly higher in the SHA $(p<0.001)$ than in the AMB groups, and significantly higher $(p<0.001)$ in both the 100 and $500 \mathrm{ppm} C O$ groups than in the $0 \mathrm{ppm} \mathrm{CO}$ groups. Although there was no significant interaction between SHA and $100 \mathrm{ppm} \mathrm{CO}$ on hematocrit ratio, there was a significant interaction $(p<0.001)$ between SHA and $500 \mathrm{ppm}$ CO.

The MEA was shifted to the right by SHA, and shifted to the left by $\mathrm{CO}$ (Table 1; Fig. 4 A,B). The MEA was significantly greater $(p<0.001)$ in the SHA compared to the AMB groups, in both the 100 and $500 \mathrm{ppm}$ CO Studies. The magnitude of the MEA was less in the 100 and $500 \mathrm{ppm} \mathrm{CO}$ groups than in the $0 \mathrm{ppm} \mathrm{CO}$ groups, but the differences were not statistically significant. There 

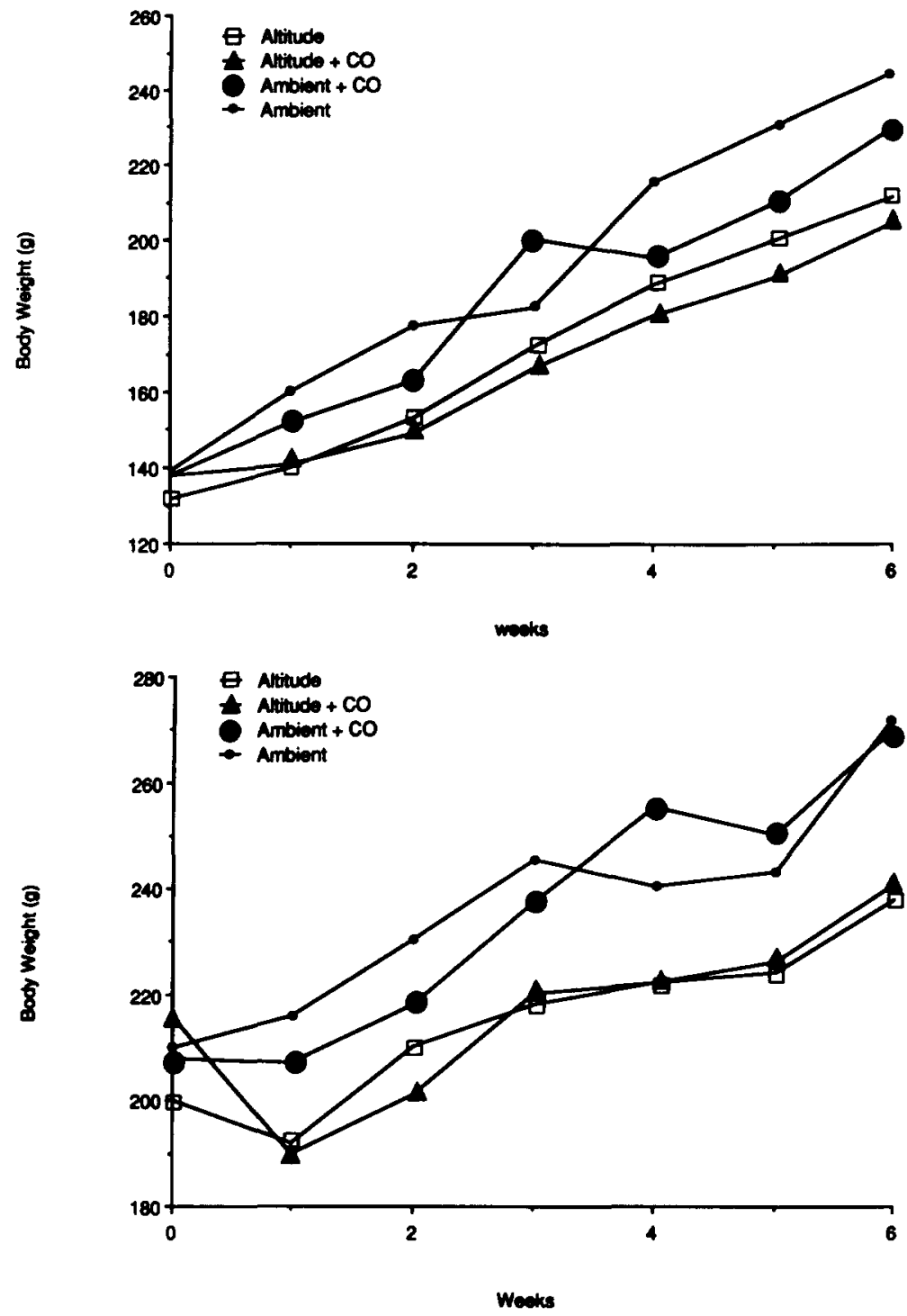

FIG. 2. Effects on body weight of exposure to (upper) $100 \mathrm{ppm} \mathrm{CO}$, and (lower) $500 \mathrm{ppm}$ $\mathrm{CO}$, at 15,000 feet.

was a significant interaction $(p<0.05)$ between SHA and $500 \mathrm{ppm}$ $\mathrm{CO}$ on the magnitude of the MEA.

\section{DISCUSSION}

Body weight, decreased significantly by SHA, was unaffected by either 100 or $500 \mathrm{ppm} \mathrm{CO}$. This observation is in accord with others who report that altitude, depending on the intensity of the exposure, depresses body weight by decreasing both caloric intake and food utilization (1). The decrease in body weight at SHA was not intensified by simultaneous exposure to $\mathrm{CO}$.

Both SHA and CO increased hematocrit ratio. There was no significant interaction between SHA and $100 \mathrm{ppm} \mathrm{CO}$ on hematocrit ratio, but there was a significant interaction between SHA and $500 \mathrm{ppm} \mathrm{CO}$. An increased red blood cell mass maintains oxygen delivery to the tissues during sustained SHA or COhypoxia. However, because of the increased work required to pump the more viscous blood, not all investigators agree that this response is beneficial to the organism. Guyton and Richardson (4) suggest that changes in hematocrit ratio affect not only the oxygen-carrying capacity of blood, but blood flow to the tissues as well. Consequently, if hematocrit ratio increases much above normal, blood flow may decrease and oxygen delivery to the tissues may be reduced. This reduction in blood flow can more than offset the increased oxygen-carrying capacity of the blood. Smith and Crowall (14) conclude that there is an optimum hematocrit ratio at sea level that shifts to a higher value with altitude acclimation. We did not attempt to determine if oxygen delivery to the tissues was compromised by the increased hematocrit ratios observed in these studies.

A major emphasis of this study was to determine if $\mathrm{CO}$ shifts the position of the MEA of the heart, and if altitude influences the magnitude of this shift. SHA alone shifted the MEA toward the right; the rightward shift in MEA at altitude is known to be caused by right ventricular hypertrophy. Right ventricular hypertrophy occurs secondarily to the pulmonary hypertension that is common in altitude-exposed animals $(3,12)$. Milledge $(7)$ concludes that pulmonary hypertension along with a high hematocrit leads to 


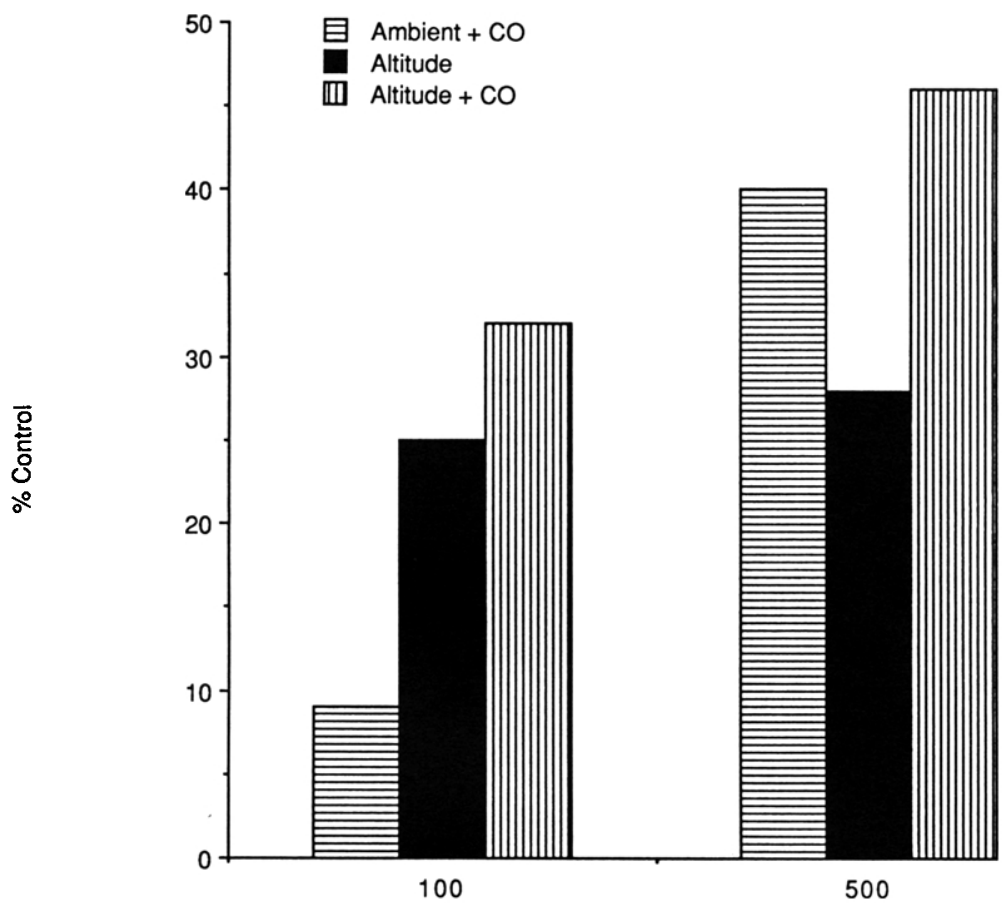

FIG. 3. Effects on hematocrit ratios of exposure to $100 \mathrm{ppm} \mathrm{CO}$, and $500 \mathrm{ppm} \mathrm{CO}$ at 15,000 feet. Data expressed as percent of control (ambient $+0 \mathrm{ppm} \mathrm{CO}$ ).

TABLE 1

MEAN ELECTRICAL AXES ${ }^{a}$ IN RATS EXPOSED TO 100 PPM CO, AND 500 PPM CO AT 15,000 FEET

\begin{tabular}{lcc}
\hline Treatment & $\begin{array}{c}100 \mathrm{ppm} \mathrm{CO} \\
\text { (Degrees) }\end{array}$ & $\begin{array}{c}500 \mathrm{ppm} \mathrm{CO} \\
\text { (Degrees) }\end{array}$ \\
\hline Ambient & $40.5 \pm 9.1$ & $48.2 \pm 10.9$ \\
Ambient $+\mathrm{CO}$ & $(12)$ & $(6)$ \\
Altitude & $27.0 \pm 4.8$ & $16.0 \pm 10.6$ \\
Altitude $+\mathrm{CO}$ & $(12)$ & $(6)$ \\
& $67.1 \pm 3.6 \dagger$ & $79.7 \pm 30.2 \dagger$ \\
& $65.0 \pm 10.3$ & $(6)$ \\
& $(12)$ & $(5)$
\end{tabular}


Two-way ANOVA used to test treatment effects.

${ }^{*} p<0.05 ; \dagger p<0.01$.

increased work for the right ventricle and this results in right ventricle hypertrophy. Milledge's report on the 1960-61 Himalayan Scientific and Mountaineering Expedition examined the ECG changes that occur at altitude. ECG's were taken after the subjects had reached the desired altitude $(17,500-19,000 \mathrm{ft})$, and again while breathing oxygen. When the subjects breathed oxygen the right axis deviation returned to the sea-level position; these workers conclude that there is a critical time of chronic hypoxia, after which changes in the right ventricle or pulmonary circulation are not reversed by relatively short periods of oxygen breathing. We feel that the 6 week exposure for our study was beyond the critical time, and an earlier report on heart weights supports this notion (6). SHA shifted the MEA to the right even in the presence of $100 \mathrm{ppm}$ CO. This suggests that at $15,000 \mathrm{ft}$ and $100 \mathrm{ppm}$, right ventricle preponderance is still the dominant feature.

$\mathrm{CO}$ shifted the MEA to the left, and the shift was greater with $500 \mathrm{ppm} \mathrm{CO}$ than with $100 \mathrm{ppm} \mathrm{CO}$. The leftward shift in the MEA with chronic $\mathrm{CO}$ is caused by left ventricular hypertrophy which is produced by a volume overload of the left ventricle. Penney and co-workers $(10,11)$ have shown cardiac enlargement in rats exposed to $500 \mathrm{ppm} \mathrm{CO}$ for up to 42 days. At $500 \mathrm{ppm} \mathrm{CO}$, both the right and left ventricles were enlarged and cardiac output was increased by an increased stroke volume. These workers conclude that the greater heart work required to provide adequate oxygenation of the tissues in the presence of $\mathrm{CO}$ hypoxia is the major factor responsible for $\mathrm{CO}$-induced cardiomegaly, and that $\mathrm{CO}$ produces a volume overload rather than a pressure overload on the heart. The dramatic shift in MEA observed with $500 \mathrm{ppm}$ at SHA is probably caused by the SHA-induced right ventricle hypertrophy combined with the total cardiac hypertrophy induced by $500 \mathrm{ppm}$ as reported in the Penney studies.

\section{ACKNOWLEDGEMENTS}

I wish to thank Debbie Parker for reviewing and typing this manuscript. "Research described in this article is conducted under contract to the Health Effects Institute (HEI), an organization that supports the conduct of independent research and is jointly funded by the United States Environmental Protection Agency (EPA) and automotive manufacturers. Publication here implies nothing about the view of the contents of HEI or its research sponsors. HEl's Health Review Committee may comment at any time and will evaluate the final report of the project. Additionally, although the work described in this document has been funded in part by the U.S. Environmental Protection Agency under assistance agreement X808859 with HEI, the contents do not necessarily reflect the view and policies of the Agency; nor does mention of trade names or commercial products constitute endorsement or recommendation for use." 
A

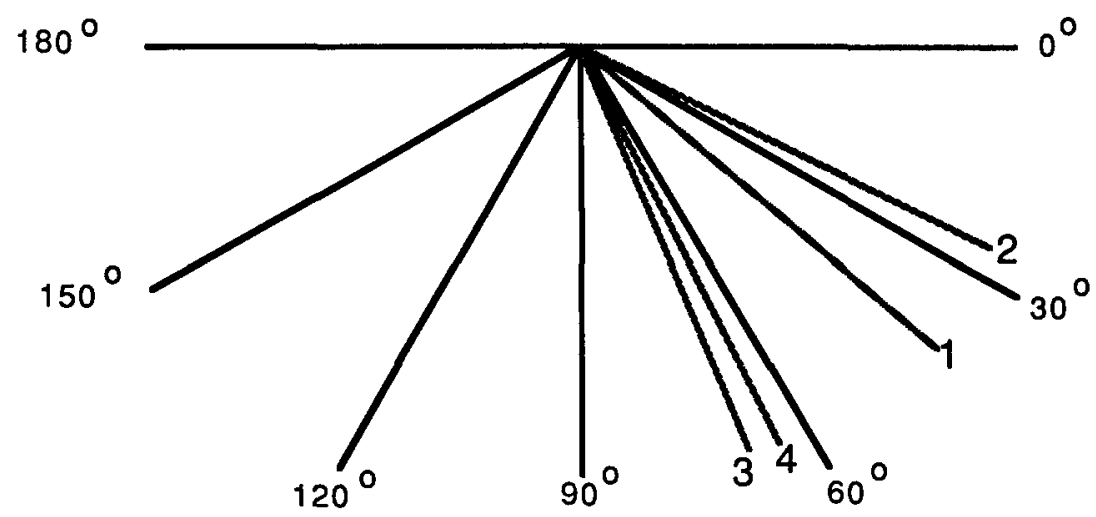

B

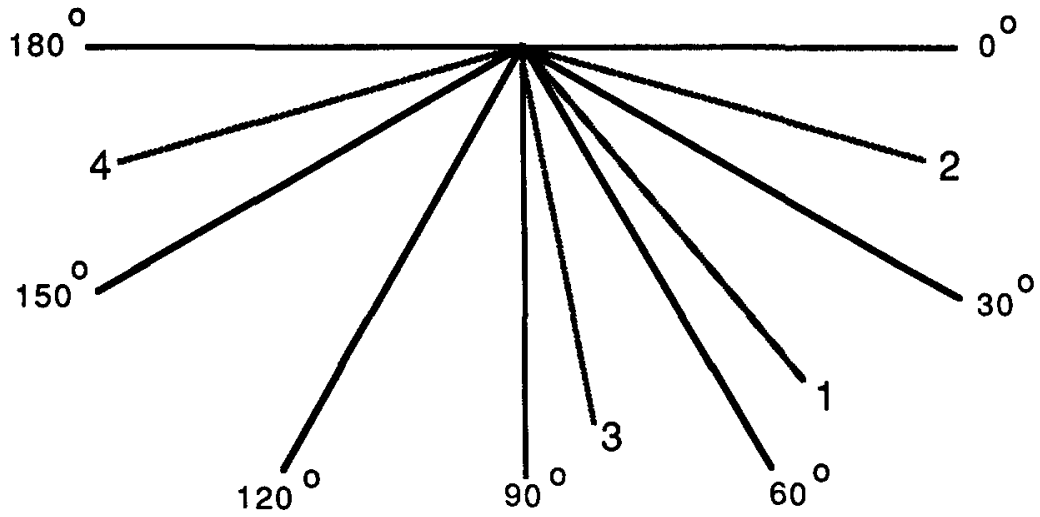

FIG. 4. Effects on mean electrical axes of exposure to (A) $100 \mathrm{ppm} \mathrm{CO}$, and (B) $500 \mathrm{ppm} \mathrm{CO}$ at 15,000 feet. Labeled lines: 1-Ambient, 2-Ambient + CO, 3-Altitude, 4-Altitude + CO.

\section{REFERENCES}

1. Blume, F. D. Metabolism and nutrition at altitude. In: Sutton, J. R.; Houston, C. S.; Jones, N. L., eds. New York: Alan R. Liss, Inc.; 1983:311-316.

2. Burch, G. E.; Winsor, T. A primer of electrocardiography. 2nd ed. Philadelphia, PA: Lea and Febiger; 1953.

3. Grover, R. F.; Reeves, J. T.; Will, D. H.; Blount, S. G., Jr. Pulmonary vasoconstriction in steers at high altitude. J. Appl. Physiol. 18:567-574; 1963.

4. Guyton, A. C.; Richardson, T. Effect of hematocrit on venous return. Circ. Res. 9:157-164; 1967

5. McGrath, J. J. Physiological effects of carbon monoxide. In: McGrath, J. J.; Barnes, C. D., eds. Air pollution-physiological effects. New York, NY: Academic Press; 1982:137-145.

6. McGrath, J. J. Chronic exposure to carbon monoxide at high altitude: Effects on heart and organ weights. J. Toxicol. Environ. Health 23(3):21-28; 1988.

7. Milledge, J. S. Electrocardiographic changes at high altitude. $\mathrm{Br}$. Heart J. 25:291-298; 1963.

8. National Research Council (NRC). "Carbon Monoxide." Committee on Medical and Biological Effects of Pollutants, Washington, DC: Natl. Acad. Sci.; 1977.

9. Penney, D.; Benjamin, M.; Dunham, E. Effect of carbon monoxide on cardiac weight as compared with altitude effects. J. Appl. Physiol. $37: 80-84 ; 1974$.

10. Penney, D. G.; Sodt, P. C.; Cutilletta, A. Cardiodynamic changes during prolonged carbon monoxide exposure in the rat. Toxicol. Appl. Pharmacol. 50:213-218; 1979.

11. Penney, D. G.; Baylerian, M. S.; Thill, J. E.; Fanning, C. M. Yedavally, S. Postnatal carbon monoxide exposure: immediate and lasting effects in the rat. Am. J. Physiol. 243:H328-H339; 1982.

12. Reeves, J. T.; Wagner, W. W., Jr.; McMurtry, I. F.; Grover, R. F. Physiological effects of high altitude on the pulmonary circulation. In: Shaw, D. R., ed. Environmental physiology III. Baltimore: University Park Press; 1979:289-310.

13. Small, K. A.; Radford, E. P.; Frazier, J. M.; Rodkey, F. C.; Collison, H. A. A rapid method for simultaneous measurement of carboxy- and methemoglobin in blood. J. Appl. Physiol. 31:154-160; 1971.

14. Smith, E.; Crowall, J. Role of increased hematocrit in altitude acclimatization. Aerospace Med. 38:39-43; 1967.

15. Van Liere, E. J.; Stickney, J. C. Hypoxia. Chicago: University of Chicago Press; $1963: 31-60$.

16. Wilks, S. S.; Tomashefski, J. F.; Clark, R. T. Physiological effects of chronic carbon monoxide. J. Appl. Physiol. 14:305-310; 1959. 